\title{
Koinonia transcorporal em tempo de pandemia
}

\author{
Transcorporal koinonia in pandemic time
}

\author{
Luiz Tarquinio Pontes
}

\section{Resumo}

O distanciamento social causado pela pandemia da COVID-19 ensejou mudanças significativas na logística do relacionamento entre os indivíduos. Objetivando evitar a contaminação e o alastramento do vírus na comunidade, adotou-se uma série de medidas profilática a fim de manutenir a saúde pessoal e comunitária. Esta situação influenciou diversos relacionamentos: familiar, profissional e eclesial, que passaram a ser desenvolvidos com maior regularidade por meio das mídias virtuais. Este artigo, valendo-se de fontes bibliográficas como metodologia, estudou o impacto desta nova economia relacional, analisando até que ponto haveria legitimidade de uma prática comunitária cristã eminentemente virtual, trazendo à baila a noção antropológica do corpo humano como componente fundamental para o desenvolvimento relacional saudável, no seio da Igreja cristã. Após analisar os mecanismos de interação social instrumentalizados pela Internet, concluiu-se que tais logísticas não cumprem eficazmente com os propósitos comunitários cristãos, exceto em estado de necessidade, como o vivenciando hodiernamente, pois o corpo é fundamental para a ocorrência de uma comunhão plena.

Palavras-chaves: COVID-19. Igrejas virtuais. Celebrações online. Nova comunhão. Cristianismo virtual.

\section{Abstract}

The social distance caused by the COVID-19 pandemic, led to significant changes in the logistics of the relationship between individuals, 
aiming to avoid contamination and the spread of the virus in the community. Thus, a series of prophylactic measures were adopted in order to maintain personal and community health. This context influenced several relationships: family, professional and ecclesial, which started to be developed commonly through virtual media. This article, using bibliographic theoretical capital as a methodology, studied the impact of this new relational economy, analyzing the legitimacy of an virtual community practice, bringing up the anthropological notion of the human body as a fundamental component for relational development, especially within the Christian community. After analyzing the mechanisms of social interaction exploited by the Internet, it was concluded that such logistics do not effectively fulfill Christian community purposes, except in times of exception, such as experiencing it today, because the body is fundamental for the occurrence of communion.

Keywords: COVID-19. Igrejas virtuais. On-line service. New fellowship. Virtual Christianity.

\section{Introdução}

A pandemia da COVID-19 impulsionou significativamente as novas logísticas de relacionamento humano, mormente aqueles praticados por intermédio das mídias sociais. A fim de viabilizar a perpetuação dos contatos entre os indivíduos, resguardando, ao mesmo tempo, os conviventes de possíveis contaminações, uma revolução comunicativa foi levada à cabo, transformando radicalmente a interação entre os humanos, macro-dimensionando o que já estava sendo praticado em nichos mais restritos.

A vida foi transformada num webinar contínuo nos mais variados setores sociais. A relação intersubjetiva passou a ser mediada por câmeras, computadores, microfones e fibras-ópticas. Esta mudança paradigmática ocorreu numa velocidade frenética, solicitando uma adaptação de urgência entre todos aqueles que pretendiam dar continuidade aos seus respectivos vínculos relacionais. Esta realidade atingiu inúmeros setores, inclusive a Igreja, povo relacional por essência e vocação, ente do "dois ou mais", ligado por elos comunitários.

O cristianismo é sempre eclesial, assembleia dos que vivem misturados, religião do conjunto, mais comunitária do que particular. Ser cristão é 
implantar-se no próximo, tornando-se parte integrante de um grande "nós". A categoria cristã carrega em si veios intrínsecos de pluralidade. Desta forma, não há viabilidade de um cristianismo à revelia da comunhão. Pretende-se, desde já, restringir o termo polissêmico "comunhão" para defini-lo, no estudo sub examen, como a vivência comunitária, prática de vida conjunta, recheada de ligamentos relacionais, onde os indivíduos participam fraternamente da vida do outro, como vingava, numa dimensão mais ideal, nas experiências da Igreja primitiva contida em Atos dos Apóstolos:

Desse modo, os que acolheram a sua palavra foram batizados; e naquele dia juntaram-se a eles quase três mil pessoas. E eles perseveravam no ensino dos apóstolos e na comunhão, no partir do pão e nas orações. Em cada um havia temor, e muitos sinais e feitos extraordinários eram realizados pelos apóstolos. Todos os que criam estavam unidos e tinham tudo em comum. Vendiam suas propriedades e bens, e os repartiam com todos, segundo a necessidade de cada um. E perseverando de comum acordo todos os dias no templo, e partindo o pão em casa, comiam com alegria e simplicidade de coração, louvando a Deus e contando com o favor de todo o povo. E o Senhor lhes acrescentava a cada dia os que iam sendo salvos (At 2,41-47).

A questão que surge como proposta do presente artigo concerne ao problema de uma visão comunitária cristã virtualizada, sem a presença do corpo humano. Até que ponto o corpo seria indispensável para o exercício da comunhão cristã? Estes são alguns dos problemas que o artigo se propõe a analisar.

\section{Igreja: povo relacional}

Uma das definições festejadas pelo Vaticano II é a realidade da Igreja como Povo de Deus. Dispõe a Lumem Gentium, número nove:

Foi Cristo quem instituiu esta nova aliança, isto é, o novo testamento em seu sangue (1Cor 11,25), chamando o Seu povo de entre os judeus e os gentios, para formar um todo, que junto crescesse para a unidade, não segundo a carne, mas no Espírito, e fosse o novo Povo de Deus. Na verdade, os que creem em Cristo, os que renasceram não de semente corruptível, mas incorruptível pela palavra do Deus vivo (1Pd 1,23), não da carne, mas da água e do Espírito Santo (Jo 3,5-6), são finalmente constituídos 
em "raça escolhida, sacerdócio real, nação santa, povo adquirido... que outrora não eram, mas agora são Povo de Deus" (1Pd 2,9-10). ${ }^{1}$

O corolário lógico da definição da Igreja como povo é o consequente relacionamento entre seus membros. Há falha na compreensão quando se admite a possibilidade de um povo cujos quadros não convivam ou se relacionem. Ao contrário, o relacionamento é parte inafastável da ontologia comunitária. "A autocompreensão da comunidade eclesial se dá pelo desígnio de os santos (hoi hágioi)", ${ }^{2}$ e ser santo é afastar-se de conteúdos axiológicos de determinados sistemas para juntar-se aos contidos no cabedal pedagógico do Nazareno. É via de saída e chegada, ao mesmo tempo. Distancia-se de laços antigos para amarrar-se a outros mais novos. Deixa-se a "nação de origem" para iniciar uma jornada relacional com uma distinta. Não há povo de Deus, portanto, sem ligamentos relacionais internos, fortes e densos.

Ao escrever aos cristãos domiciliados em Éfeso, o apóstolo Paulo afirma:

Antes, seguindo a verdade em amor, cresçamos em tudo naquele que é a cabeça, Cristo. Dele todo o corpo, ajustado e unido pelo auxílio de todas as juntas, cresce e edifica-se a si mesmo em amor, na medida em que cada parte realiza a sua função. Assim, eu lhes digo, e no Senhor insisto, que não vivam mais como os gentios, que vivem na futilidade dos seus pensamentos (Ef 4,15-17).

Observa-se no excerto epigrafado, a existência de um Corpo e suas respectivas partes, que se auxiliam mutuamente na medida que realizam suas respectivas funções. Da mesma forma que no corpo humano os órgãos se ajustam em reciprocidade e dependência uns dos outros, assim também acontece na Igreja. Esta simbiose requer proximidade e relação para se realizar. A ideia de Povo de Deus outorga à Igreja um caráter histórico, peregrina no tempo, que transita no tempo em companhia de outros. ${ }^{3}$ É com as mãos dadas, os pés juntos e os pesos compartilhados que se faz transeunte. A amputação de tais processos a torna claudicante.

A Igreja é um povo em relação, uma comunidade intercambiante, cujos membros são ao mesmo tempo doadores e donatários, ofertando e auferindo

\footnotetext{
${ }^{1}$ LG 9.

${ }^{2}$ SANTOS, J. B. R., Santidade, p. 464.

${ }^{3}$ BOFF, L., O coronavírus desperta o humano em nós, p. 124.
} 
insumos espirituais a partir dos dons recebidos do Espírito. É neste ajustamento que se encontra a porção da Igreja, sem a qual reduz sua imanência, diluindo-se em meio à realidades meramente metafísicas. Ou seja, a Igreja "aqui" é a que se tem, cadinho onde se cumprem e estabelecem relações entre seus componentes. Colocando entre parênteses as misturas cristãs, o relacionamento entre o povo, o ligamento intersubjetivo, a Igreja se transforma em mera categoria teórica e nominal, um fenômeno presente tão somente na consciência, mas distante de peles, mãos e corações. O relacionamento entre os membros da Igreja é o seu sangue, que, esvaziado, somente resta a exumação.

Etimologicamente, o vocábulo "igreja" advém do termo ekklēsia, que significa "assembleia", "congregação". O vocábulo ocorre 114 vezes no Novo Testamento. ${ }^{4} \mathrm{O}$ termo, por sua vez, remonta às reuniões que aconteciam na ágora em Atenas, onde os cidadãos se reuniam para discutir assuntos concernentes à pólis e deliberar acerca dos problemas de interesse comum. ${ }^{5}$ Cada vez que se ajuntavam para dialogar, instalava-se, portanto, a ekklēsia. A partir do início das reuniões, os cidadãos, que levavam a alcunha de eccletoi, discursavam e ouviam os discursos uns dos outros. ${ }^{6}$ Isto é, nas inerências do termo, está imbricada a noção de relacionamento, comunidade, diálogo e partilha.

$\mathrm{Na}$ Septuaginta, o termo grego ekklēsia é o vocábulo mais utilizado para efetivar a tradução da palavra hebraica qahāl, contida no Antigo Testamento, geralmente traduzida por "congregação", "assembleia" do povo de Deus. A utilização desta tradução é praticada por 69 vezes. A outra tradução frequente, também, para o termo qahāl é synagōge, "sinagoga" ou "lugar de reunião", ocorrendo 37 vezes. $^{7}$

Lumem Gentium compara a Igreja a uma grande família que comunica caridade e louvor a Deus, in verbis:

Pois, com efeito, todos os que somos filhos de Deus, e formamos em

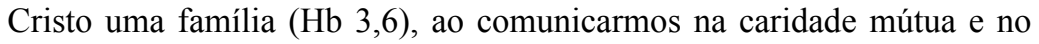
comum louvor da Trindade Santíssima, correspondemos à íntima vocação da Igreja e participamos, prelibando-a, na liturgia da glória. ${ }^{8}$

\footnotetext{
${ }^{4}$ WILLIAMS, J. R., Teologia Sistemática, p. 755.

${ }^{5}$ ARANHA, M. L. A.; MARTINS, M. H. P., Filosofando, p. 39.

${ }^{6}$ KITTEL, G., Eclesia, p. 513.

${ }^{7}$ GRUDEM, W., Teologia Sistemática atual e exaustiva, p. 729.

${ }^{8}$ LG 51 .
} 
Não é distinta a ideia contida na carta aos Gálatas: “Assim, enquanto temos oportunidade, façamos o bem a todos, principalmente aos da família da fé" (Gl 6,10). Os componentes da Igreja se relacionam, portanto, como uma grande família.

Há diversas metáforas que comparam a Igreja a uma grande família. ${ }^{9}$ Por exemplo, Paulo ensina ao seu discípulo Timóteo, que agisse como se todos pertencessem a uma família: "Não sejas duro na repreensão ao idoso, mas exorta-o como a um pai; aos jovens, como a irmãos; às mulheres idosas, como a mães; às jovens, como a irmãs, com toda pureza" (Tm 5,1-2). Ademais, por inúmeras vezes, o apóstolo Paulo, atribui a graça de "irmãos" aos pertencentes aos quadros eclesiais, verbi gratia, o prefácio contido na Carta aos Colossenses, que diz: "Paulo, apóstolo de Cristo Jesus pela vontade de Deus, e o irmão Timóteo, aos santos e fiéis irmãos em Cristo que estão em Colossos: Graça a vós e paz da parte de Deus nosso Pai" $(\mathrm{Cl} 1,1-2)$.

Ora, uma das características mais expressivas de uma família é a convivência, o relacionamento entre os membros que a compõem. A família é o seio de maior intimidade comunitária. A proximidade e a ambiência comum ensejam laços relacionais coesos e densos. Na família, o ser-humano despe-se de todas as coberturas que conduzem ao afastamento. A família é o foro relacional por essência, onde o ser é o que ele mais é, mais ele mesmo do que em qualquer outro lugar, é o lugar da experiência nua, onde os variados cobertores sociais são suspensos e a vida adquire maior autenticidade. Exatamente por ser uma grande família, a Igreja é uma sociedade interfacial, vinculada desde as origens a partir de relacionamentos entre os sujeitos que a compõem.

As narrativas bíblicas reverberam implicitamente o viés relacional do ser humano, que não fora criado para viver sozinho e ilhado. "Disse mais o SENHOR Deus: Não é bom que o homem esteja só; eu lhe farei uma ajudadora que lhe seja adequada" (Gn 2,18). Para um homem, uma mulher, e vice-versa. O relacionamento entre humanos é tão antigo quanto eles mesmos. Dispensando-se a relação, a própria vida pereceria. Para existir, necessária se torna aproximação e enlaces. A própria estrutura divina carrega no bojo veios de pluralidade e relação entre ela: Deus Pai, Filho e Espírito Santo. O humano sozinho é sempre parcial. É na comunidade que se humaniza integralmente. Quando se implode pontes entre sujeitos, constrói-se paredes divisórias que singulariza o que somente cabe no plural.

${ }^{9}$ GRUDEM, W., Teologia Sistemática atual e exaustiva, p. 718. 
A Igreja é sociedade relacional por vocação. Descontruir-se-ia sua marca peculiar e carisma ao menoscabar a importância do relacionamento entre seus constituintes. O conceito de Igreja carrega no íntimo a noção de intersubjetividade. Na Carta aos Romanos, reza o apóstolo Paulo: "Pois assim como em um corpo temos muitos membros, e todos os membros não têm a mesma função, assim também nós, embora muitos, somos um só corpo em Cristo e, individualmente, membros uns dos outros" (Rm 12,4-5). O cristianismo é sempre eclesiástico, antes comunitário do que solo e privativo. Ser cristão é se tornar peça que se acopla, tornando-se parte integrante de outrem. Em última instância, o conceito de cristão é sempre relacional e simbiótico.

$\mathrm{O}$ desafio que permanece, entretanto, concerne à práxis. Diz respeito às estruturas logísticas das práticas comunitárias e relacionais, ainda mais na tecitura social contemporânea do mundo virtual, onde vige relacionamentos híbridos, destituídos dos formatos ortodoxos e tradicionais, que requeriam presença física para se concretizar. Na contemporaneidade, o relacionar-se está sofrendo uma virada de esquina, grande curva em sua administração. A interação, no momento atual, independe da presença física. Pode-se dialogar e ver o interlocutor com o qual se interage, sem necessitar aproximação corporal. A videoconferência tomou lugar dos encontros e reuniões presenciais. Aplicativos de celular, programas de computador, como Zoom, Google Hangouts e Skype se tornaram instrumentos fundamentais para o trabalho e a socialização, mas o acúmulo de atividades nesses meios virtuais pode trazer fraturas relacionais importantes. ${ }^{10}$

A utilização de ferramentas de videoconferência transformou o ocasional em perene, a exceção em regra. As lives viraram rotina durante a pandemia. Nota-se, no entanto, que uma posologia inadequada no manuseio do instrumental pode trazer malefícios. A nova realidade gestada pela COVID-19 obrigou todos a se adaptarem com velocidade à nova interatividade, transformando a rotina e os meios tradicionais de comunicação, inclusive nos redutos eclesiásticos. Cultos, missas, encontros familiares, cursos de casais, tudo sendo realizado à distância, devido a medidas profiláticas para evitar a disseminação do vírus. $\mathrm{O}$ toque foi abolido e temido, o corpo se transformou em ameaça, os rostos se disfarçam por meio de máscaras que dificultam o movimento patológico do vírus. Tais medidas, ao mesmo tempo que resguarda a bios, a vida orgânica, maculam a zoe, a relação in natura, em sociedade.

${ }^{10}$ LANCHA, L.; LANCHA Jr., A. H., A fadiga do Zoom e dos encontros e reuniões virtuais, p. 01. 


\section{A nova comunhão}

Esta nova situação não deixou desafetado os relacionamentos comunitários no seio da Igreja. Como ente humano e divino, celestial e terreno, a Igreja é composta de pessoas reais, sensíveis a vicissitudes e intempéries temporais. A Igreja não se resguarda das dinâmicas comuns da vida, como se estivesse no interior de uma cápsula protetora, blindada contra os impactos comuns da natureza. $\mathrm{O}$ povo de Deus é peregrino e estrangeiro. Não pertence à presente historicidade, mas caminha por ela, por suas estradas iluminadas e, também, esquinas turvas. A caminhada da Igreja à "Terra Prometida" não chegou à linha final, o caminho ainda é caminhando, não caminhado.

Devido a esta realidade, a Igreja também foi impactada pelos tentáculos do coronavírus, que encastelou novamente os humanos nas "cavernas", por intermédio dos ácidos e prolongados períodos de quarentena e rígido distanciamento. Tal fato afetou mais do que aos homens à humanidade, sem distinções racial, social, econômica e cultural, em demonstração da forte simbiose entre a espécie homosapiensiana. A marca democrática da COVID-19 ofertou uma claridade ainda maior de interdependência e enlace entre as pessoas. O ser-humano é uma espécie lançada em um mundo que é seu, mas também de outros ao mesmo tempo, e, nesta economia, é invadido, também, pelo que a outros invade. Esse condomínio em relação ao oikos produz tecituras íntimas e intensas entre os humanos, que somente é um-com-o-outro.

O homo insulam, autônomo, independente, alheio aos pares, é homem impossível. Homens são plurais ou desumanizados. A pandemia logrou demarcar rigorosamente a influência intensa do conjunto humano sobre seus componentes, maculando as ideologias individualistas, que exaltam o singular em detrimento do plural. Como afirmou Boff: "Somos seres de relação. Somos, como tenho repetido inúmeras vezes, um nó de relações totais voltadas em todas as direções. Portanto, ninguém é uma ilha. Lançamos pontes para todos os lados". ${ }^{11} \mathrm{O}$ ser-humano é eminentemente ente relacional, ou seja, sua existência se condiciona em relação-a-outro, grampeando a marca da inerente interdependência.

Todos são dependentes. A expressão bastante popular no continente africano "Ubuntu" coloca afinadamente: "eu só sou eu através de você". A saúde física das pessoas está mais associada ao outro do que se poderia imaginar

${ }^{11}$ BOFF, L., O coronavírus desperta o humano em nós, p. 124. 
antes da pandemia. Esta dependência e alteridade chama-se solidariedade. ${ }^{12}$ A realidade de tal condicionamento direcionou o foco de luz lançado pela pandemia mais para o conceito integral de humanidade e de povo - dandolhe maioridade - do que para as singularidades, enfraquecendo a autonomia do "só", que recheia os paradigmas individualistas. O ser-humano por ser humano é conjugativo.

Com a pretensão de manter os ligamentos de comunhão entre seus membros e evitar as possibilidades de contaminação pelo novo vírus, muitas porções eclesiais fomentaram a prática de cultos e missas online, reunião de grupos familiares pela internet, entre outros movimentos comunitários não presenciais. O que já acontecia no período pré-pandêmico - haja vista a existência de diversos programas celebrativos online - popularizou-se exponencialmente devido aos cuidados profiláticos para se resguardar de uma possível disseminação do COVID-19 entre os fiéis.

Delimitando tais procedimentos ao Brasil, diversas denominações cristãs suspenderam suas respectivas celebrações dominicais no templo para fazê-la de forma virtual. A Primeira Igreja Batista de Curitiba, por exemplo, a partir do início da Pandemia decidiu, por meio de seu corpo pastoral, que todos as reuniões e encontros da Igreja se dariam unicamente por via online. ${ }^{13} \mathrm{~A}$ Igreja Metodista da $3^{\text {a }}$ Região Eclesiástica decidiu que devido à pandemia, em seguimento às decisões governamentais e episcopais, realizaria cultos virtuais na forma online, promovendo, ainda, a celebração virtual da ceia do Senhor. ${ }^{14}$ A Igreja Presbiteriana do Barreto, da mesma forma, suspendeu seus cultos presencias devido à pandemia. Em março de 2020, o presidente da Igreja Evangélica Luterana do Brasil orientou seus membros e pastores a suspenderem as atividades presenciais da igreja. ${ }^{15}$ A diocese de São Carlos normatizou a suspensão dos encontros presenciais, com vista à prevenção frente ao coronavírus. ${ }^{16}$

Tais restrições foram lugar comum na maioria absoluta das Igrejas no Brasil, cujos líderes almejavam evitar o fomento da disseminação do vírus entre os fiéis. Contudo, o fato concreto é que se deu início a um modelo revolucionário de ajuntamento celebrativo, não mais como exceção mas como regra. Devido

\footnotetext{
${ }^{12}$ BOFF, L., O coronavírus desperta o humano em nós, p. 124.

${ }^{13}$ PIRAGINE Jr., P., PIB Curitiba na Pandemia.

${ }^{14}$ IGREJA METODISTA DA $3^{\text {a }}$ REGIÃO, Culto regional on-line.

${ }^{15}$ MENSAGEIRO LUTERO ONLINE, Cultos presenciais.

${ }^{16}$ CORONAVÍRUS: igrejas católicas suspendem missas presenciais em São Carlos.
} 
ao evitamento do acesso ao locus de adoração e culto, práticas eclesiásticas que requeriam a presença física do fiel para acontecer, passaram a ser praticadas à distância, sem a presença corporal do partícipe. Como elencado acima, até mesmo a participação eucarística à distância foi permitida em determinadas igrejas. Esta nova forma de encontros eucarísticos, dispensam um ingrediente tradicional que os condicionava, qual seja a presença do corpo humano.

A palavra comunhão advém do hebraico habar, que tem o sentido de "ajuntar", "unir". No grego, o termo deriva do vocábulo koinonia que expressa a ação de uma comunidade litúrgica que se reúne e ajunta para adoração. Era uma consequência de um conjunto de pessoas que receberam o Espírito Santo. ${ }^{17}$ Em Atos, lê-se:

Desse modo, os que acolheram a sua palavra foram batizados; e naquele dia juntaram-se a eles quase três mil pessoas. E eles perseveravam no ensino dos apóstolos e na comunhão, no partir do pão e nas orações. Em cada um havia temor, e muitos sinais e feitos extraordinários eram realizados pelos apóstolos. Todos os que criam estavam unidos e tinham tudo em comum. Vendiam suas propriedades e bens, e os repartiam com todos, segundo a necessidade de cada um. E perseverando de comum acordo todos os dias no templo, e partindo o pão em casa, comiam com alegria e simplicidade de coração, louvando a Deus e contando com o favor de todo o povo. E o Senhor lhes acrescentava a cada dia os que iam sendo salvos (At 2,41-47).

Os convertidos viviam juntos, compartilhando a presença e as necessidades como uma grande família ligada pelo exemplo de Jesus. A marca comunitária demonstrava as cores da Igreja. $\mathrm{O}$ relacionamento e a comunhão eram como pincéis e tintas a desenhar a grei. A efusão do Espírito gera uma explosão de senso comunitário, reduzindo as desigualdades. Quem tinha mais dividia suas posses com os menos privilegiados. Tudo acontecendo de maneira espontânea, sem regramentos e obrigatoriedades. Era uma ação vinda mais do Espírito do que de elaboração normativas eclesiais. O Espírito reduz os afastamentos e as desigualdades, o que costuma acontecer nas famílias, onde seus membros compartilham o mesmo domo communi.

Trazendo à baila o conceito de família como metáfora de Igreja, não parece possível, é o que se observa, que uma família decida desenvolver um relacionamento meramente virtual com seus membros. Causaria espécie o

${ }^{17}$ SANTOS, J. B. R., Koinonia, p. 97. 
fato de o marido decidir viver regularmente em local distinto do domicílio da esposa, nutrindo com ela relacionamentos meramente online. Certamente, um importante ingrediente estaria faltando, qual seja o corpo. Sem ele, inclusive, tal casamento não seria capaz de experimentar o desfrute pleno da sexualidade e gerar filhos. Para um processo relacional ser completo, portanto, observa a importância da participação do corpo no esquema, o que não se observa na concepção virtual de relacionamento.

De acordo com a respectiva análise, importa reconhecer que relacionamentos virtuais não se configuram completos, como se faltasse o importante tempero do corpo. O corpo é parte insubstituível das pessoas, sem o qual elas não estarão in totum no enredo relacional. Os scholars ligados à antropologia costumam adotar uma destas três teorias quando pretendem ofertar um compartilhamento ontológico do ser-humano: monismo, dicotomia e tricotomia. A primeira tese filia-se ao pensamento de que o homem é composto de um elemento único, sendo seu corpo a própria pessoa. Os dicotomistas ligam-se ao entendimento de que os humanos são forjados a partir de dois ingredientes: o corpo e a alma. Já os tricotomistas advogam a doutrina de uma divisão em três partes, quais sejam: corpo, alma e espírito. ${ }^{18}$

Importa reconhecer, destarte, que seja qual for a escola a que se filie, o corpo é parte integrante e inegociável da existência humana. Pode haver embates em relação a outros aspectos, como, por exemplo, os atinentes a viabilidade em relação a existência da alma e do espírito, mas há uníssonos em relação a existência do corpo como parte indissociável das pessoas, como testifica Grudem:

De quantas partes compõe-se o homem? Todos concordam que temos um corpo físico. A maioria das pessoas (tanto cristãos quantos não cristãos) sente que também tem uma parte imaterial - uma "alma" que sobreviverá à morte do corpo. Mas aqui termina a concordância. Algumas pessoas creem que, além do "corpo" e da "alma", temos uma terceira parte, um "espírito" que se relaciona mais diretamente com Deus. ${ }^{19}$

A existência do fenômeno corpo é imanente e concreto, não havendo muito espaço para questionamentos mais efetivos, com a pesagem necessária para juntar à presente discussão. Observa-se, assim, que a realidade do corpo

\footnotetext{
${ }^{18}$ GRUDEM, W., Teologia Sistemática atual e exaustiva, p. 388-389.

${ }^{19}$ GRUDEM, W., Teologia Sistemática atual e exaustiva, p. 388.
} 
não pode ser desligada do aspecto humano. Na teologia cristã, há insumos que corroboram a realidade antropológica do corpo como parte relevante. Segundo a narrativa de João, ao se fazer carne, Cristo se revestiu de um corpo completamente humano, isto é, Ele habitou em carne, numa dimensão integralmente humana, tornando-se Um entre pares. O apóstolo João escreve:

Ele veio para o que era seu, mas os seus não o receberam. Mas a todos que o receberam, aos que creem no seu nome, deu-lhes a prerrogativa de se tornarem filhos de Deus; os quais não nasceram de linhagem humana, nem do desejo da carne, nem da vontade do homem, mas de Deus. E o Verbo se fez carne e habitou entre nós, pleno de graça e de verdade; e vimos a sua glória, como a glória do unigênito do Pai (Jo 1,11.14).

A encarnação de Jesus fez com que participasse integralmente da realidade própria e comum dos humanos. Certamente havia algo importante na sua presença real e não virtual. Os homens deveriam vê-lo face-a-face, e não como um espécime virtualmente colocado e distante. Os encontros mais distantes, entre Deus e os homens, já ocorriam anteriormente na primeira aliança, mas, a partir do momento, que houve desejo de plenificar a relação homo-Dei a presença do corpo tornou-se indispensável.

Em acréscimo aos conceitos elencados, cabe ainda grifar o conteúdo do Credo Apostólico, que indica a realidade da ressurreição da carne na peroração do processo escatológico, in verbis: "Creio no Espírito Santo, na santa igreja católica, na comunhão dos santos, na remissão de pecados, na ressurreição da carne e na vida eterna. Amém". Isto é, a realidade celestial não será destituída de materialidade corpórea. Não será como um mundo virtual de imagens e silhuetas destituídas da presença concreta da carne. Ao contrário, segundo o Credo Apostólico, a carne será restabelecida de maneira incorruptível no tempo da ressurreição.

A partir da análise de tais realidades, importa deduzir que o ajuntamento comunitário virtual não cumpre integralmente com as prerrogativas de uma comunhão ideal, haja vista a carência de um ingrediente de importância singular para sua concretização: o corpo. As recentes configurações sociais, instrumentalizadas pelas mídias forjadas pela web, ensejam defasagem relacional, entre as quais pode-se elencar: a insensibilização comunitária, defasagem comunicativa, artificialização produzida pela aparelhagem técnica e impulsionamento desconcentrativo, como será esposado a seguir. 


\section{Possíveis consequências}

Importa verificar a legitimidade de uma logística comunitária virtual. O problema que se levanta concerne a diagnosticar se o corpo é ou não fundamental para a ocorrência da comunhão cristã. Caso a resposta seja positiva, a validação dos encontros virtualmente arranjados seria afetado. Desta forma, não poderiam ser rigorosamente considerados verdadeira comunhão. Ao passo que, legitimando-se tais processos comunitários virtuais, uma revolução eclesiológica estaria sendo radicalmente construída. Isso porque haveria a possibilidade de ser realizado à distância todos os atos e ritos litúrgicos que seriam possível presencialmente.

A pandemia da COVID-19 serviu não como engendramento de uma nova realidade social, antes favoreceu o fortalecimento de configurações já alicerçadas. O webinar transmutou-se de exceção em regra, a partir da instalação de uma economia social pandêmica. A gripe pressionou um esquema que já possuía raízes próprias, adubando o solo para o seu aprofundamento, vicejando um sistema já posto. Como afirma Rodrigues e Porto: "A realidade virtual existe há quase trinta anos, tendo se intensificado nos últimos anos". ${ }^{20}$ A clausura social funcionou, à guisa de tsunami, como encharcamento, inundação dos processos virtuais, alcançando gama inumerável de relações, devido ao receio dos contatos presenciais, pois a presença de corpos tornouse periclitante. Essa inusitada situação fomentou a busca de soluções para a manutenção de uma comunicação segura, que mantivesse uma interlocução incólume.

Desta maneira, houve uma explosão de conexões interpessoais que dispensavam a participação do corpo humano. Isso aconteceu inclusive no âmbito eclesial. Diversas liturgias, escolas bíblicas, grupos de orações começaram a ser realizadas virtualmente como medida profilática contra o alastramento do vírus. As conexões humanas se transformaram rapidamente em lives resguardando os sujeitos do touch. A ordem social tornou-se: "Mantenha distância".

Via inversa, há quem defenda:

Sendo aceito que na contemporaneidade não existe uma cisão clara e definitiva do que constitui o real e o virtual, é imprescindível tentar entender qual a extensão desses dois conceitos. Posto isso, a priori é forçoso notar que

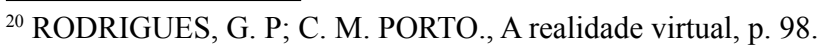


Pierre Lévy aponta o virtual como não necessariamente fazendo oposição ao real, haja vista que esta seria uma simplificação ordinária demais, o que terminaria por deixar de lado importantes considerações acerca da relação real-virtual. Em primeiro lugar, sob a consideração de não se poder pensar que o virtual é desprovido de veracidade, o que o caracterizaria como uma possível quimera. O virtual tem sua raiz em virtus, portanto é, em linhas gerais, aquilo que existe em potência. Logo, em apoio a isso é importante notar que a vivência virtual não é meramente uma negação da vida real, antes, pode ser vista como uma potência ainda carente de efetivação, mas carregada de sentido do real. ${ }^{21}$

Não obstante, o autor termina anuindo à ideia de que a virtualidade é, sim, uma potência e não uma integralidade, que reduz significativas porções de interações entre sujeitos, o que, de per si gera consequências expressivas. Ademais, pontos de defasagem comunitária, como se elencará a seguir, poderão surgir, congestionando o engajamento entre os sujeitos. As comunidades virtuais são destituídas de componentes humanos completos. Não há corpos, há fotos; não há nomes, mas apelidos - muitas vezes colocados não pelo sujeito que o detém, mas por seu interlocutor -, o que nalguma proporção fragiliza a persona. Além de tal horizonte, a comunicação muitas vezes se dá por escrito destandardizando o vínculo regular da comunicação humana mais intimista, qual seja a fala. E quando a interação é instrumentalizada pela voz, há um acréscimo exponencial de congestionamentos comunicativos, muito mais do que na dinâmica presencial.

Estas questões reduzem as porções in natura de humanidade, fazendo regredir as concepções mais peculiares das relações intersubjetivas. A diminuição da humanidade decresce seu valor e deferência, engendrando uma espécie de "faz-de-conta" conectivo, o que desperta o sentimento de anestesia da sensibilidade humana. O interlocutor é visto em humanidade esquálida, pois se assemelha a mero reflexo e imagem. O mundo virtual fomenta uma existência que não existe. A compaixão e o comprazer são deixados à inanição, haja vista a falta do rigor relacional completo.

Outro fator que acelera tal processo são os protocolos de cortes da interação. Ao se apertar um botão, clicar em determinado ícone, o maquinário relacional desconecta os partícipes automaticamente e a relação desencaixa sem os protocolos de gentileza comuns a todos os ritos de despedida. A alteridade é fragilizada, pois

${ }^{21}$ SANTOS, L. R. A., A virtualização humana, p. 191. 
o outro está presente apenas em parcela e quinhão, o que engrena uma visão ficcional do relacionamento. Esse movimento de ser-e-não-ser ao mesmo tempo, explode interrogações nos relacionantes que, devido à semelhança aos processos dramatúrgicos, desconfiam estar participando de conteúdos afinados ao mesmo alinhamento. Esta é uma das características do mundo virtual.

Segundo o léxico o termo "virtual" significa algo "que não existe como realidade, mas sim como potência ou faculdade; que é suscetível de exercerse embora não esteja em exercício". ${ }^{22}$ Isto é, a virtualidade seria, pois, tão somente potência de realidade, reflexo. Assim como a imagem refletida no espelho não é a coisa em si, o virtual configura-se como mera potência. Rodrigues e Porto elucidam:

Existe uma extensa quantidade de definições sobre realidade virtual, de forma geral, elas fazem referência a uma imersiva e interativa experiência que se baseia em imagens gráficas 3D geradas por computador em tempo real, em outras palavras, é uma simulação de um mundo real, ou apenas imaginário gerada por computador. ${ }^{23}$

As mídias sociais não produzem relacionamento, mas unicamente seu reflexo. A virtualidade dispensa inúmeros aspectos pessoais. O serhumano não se conforta por meio de reduções em simulacros de fotos e imagens por mais sensação de realidade que possuam, mas são recheados de transcendências, dinamicidade e dimensões complexas que se fazem mais presentes onde se apresentam em inteireza corporalmente. Há áureas que não se conseguem enxergar na web e que enseja ligamentos insubstituíveis entre as pessoas. Os corpos possuem comunicabilidades próprias que não se manifestam virtualmente, o que emborra a integridade de relacionamentos não presenciais. As pessoas possuem nomes e sobrenomes, não nicknames. As interlocuções comunicam sem as equalizações próprias que brotam com a presença do corpo, o que maquiniza o processo relacional com inúmeros ruídos comunicativos e congestionamentos a macular a máxima fruição das interfaces. As atuais máquinas de relacionamentos virtuais corroboram para conexões miniaturizáveis.

Um outro fato que dificulta a relação virtual, mormente nos processos comunitários cristãos, é o impulsionamento desconcentrativo. A estada em

${ }^{22}$ PRADO E SILVA, A., Virtual, p. 880.

${ }^{23}$ RODRIGUES, G. P; PORTO, C. M., Realidade virtual, p. 99. 
um ambiente completamente envolvido na tarefa de comunhão facilita sua ocorrência. O lugar onde se passou a realizar os processos de comunhão cristã, também é lugar da academia, estação de trabalho, espaço para variados tipos de lazer, entre outras coisas. ${ }^{24}$ Isso torna mais difícil a realização do processo de comunhão, desconsiderando o fato da saturação das tantas relações virtuais já requeridas regularmente, e que requer esforço para se desenvolver.

A fluidez dos movimentos comunicativos, as dinâmicas corporais aproximativas, o calor da presença acolhedora, perdem-se no mundo virtual, onde o incentivo está na desconcentração e onde se movimentam diversos e distintos interesses ao mesmo tempo, obstruindo o enredo principal. "Muitos dos programas utilizados para essas chamadas e reuniões possuem a ferramenta de chat, útil na troca de informação, mas que também pode levar à distração com conversas paralelas". ${ }^{25}$ A ausência do corpo produz uma diminuição concentrativa natural, gera frieza, engrena desatenção, obstando a pureza comunitária. Por mais bem produzida que seja um tour virtual num destino sonhado, nada se compara a estar ali presencialmente.

Por fim, toda a aparelhagem técnica necessária para a efetivação dos movimentos comunitários virtuais, fomenta um relacionamento de sabor industrializado. A mecânica da artificialidade impele a desconfiança de que as pessoas com as quais se está relacionando seguem o mesmo esquema manufaturado. Esses vetores auxiliam a aderência artificialista da relação comunitária, visualizada meramente como potência e simulacro, não como verdadeira e real, impulsionando processos desvalorativos de humanidade.

\section{Conclusão}

A nova realidade frente à pandemia de COVID-19 compeliu mudanças bruscas no modus operandi dos movimentos profissionais e comunitários. Isso não deixou a Igreja à revelia. Esta também teve que proceder rapidamente diversos artifícios para se modelar à nova realidade, caso quisesse continuar ofertando assistência aos fiéis. A questão em foco é compreender os variados efeitos práticos destas respectivas conexões virtuais, sua correção e legitimidade no âmbito teológico, com vistas a fomentar uma análise mais

${ }^{24}$ LANCHA, L.; LANCHA Jr., A. H., A fadiga do Zoom e dos encontros e reuniões virtuais, p. 01.

${ }^{25}$ LANCHA, L.; LANCHA Jr., A. H., A fadiga do Zoom e dos encontros e reuniões virtuais, p. 01. 
verticalizada das práticas virtuais em voga na contemporaneidade, mormente sob a perspectiva teológica. Até que ponto uma comunhão sem o corpo pode ser considerada legítima?

A resposta a pergunta anterior parece caminhar na direção da legitimação da mesma tão somente em estado de exceção. Ou seja, na configuração de um estado de necessidade, poder-se-ia utilizar os respectivos instrumentais de comunicação virtual para levar a cabo uma interatividade comunitária cristã. Isto porque seria melhor uma comunhão a distância do que uma não-comunhão. Mas ao desquite do estado de exceção, a possibilidade da legitimação da comunhão, sem a presença do corpo, não se assemelha como via adequada, pois a integralidade do ser-humano não estaria participando do respectivo esquema relacional.

Espera-se que este texto tenha oferecido subsídios para aqueles que desejam estudar o relacionamento comunitário no seio da Igreja cristã a partir dos modelos de comunicação oferecidos pela modernidade. Combinado a este fato, o estudo avalia ser arriscado legitimar, em tempos regulares, uma dinâmica de comunhão cristã à revelia da presença física dos partícipes. Apesar de não definitivo, este artigo pretende oferecer conteúdos para que outros estudiosos e pesquisadores continuem a desenvolver o tema para um maior e melhor esclarecimento.

\section{Referências bibliográficas}

ARANHA, M. L. A.; MARTINS, M. H. P. Filosofando: Introdução à filosofia. São Paulo: Moderna, 2009.

BÍBLIA ALMEIDA SÉCULO 21. São Paulo: Editora Vida Nova, 2019.

BOFF, L. O coronavírus desperta o humano em nós, 09 abr. 2020. Disponível em $<$ https://amerindiaenlared.org/contenido/16695/el-coronavirusdespiertaen-nosotros-lo-humano/>. Acesso em: 10 fev. 2021.

CONCÍLIO VATICANO II. Constituição Dogmática Lumen Gentium. In: CONCÍLIO VATICANO II. Compêndio do Vaticano II: constituições, decretos, declarações. Petrópolis: Vozes, 1991. p. 37-117.

CORONAVÍRUS: igrejas católicas suspendem missas presenciais em São Carlos. Acidade ON - São Carlos, 5 fev. 2021. Disponível em $<$ https:// www.acidadeon.com/saocarlos/cotidiano/coronavirus/NOT,0,0,1579912, 
Coronavirus + igrejas + catolicas + suspendem + missas + presenciais + em + Sao + Carlos.aspx>. Acesso em: 09 fev. 2021.

GRUDEM, W. Teologia Sistemática atual e exaustiva. São Paulo: Vida Nova, 2010.

IGREJA METODISTA DA $3^{\text {a }}$ REGIÃO. Cultos regional on-line. Youtube, 5 abr. 2020. Disponível em: $<$ https://www.youtube.com/watch?v=Ab5rpdKbgbY>. Acesso em: 09 fev. 2021.

KITTEL, G. Eclesia. In: KITTEL, G. Theological dictionary of the new testament. Grand Rapids: Eerdmans Publishing Company, 1964. p. 513.

LANCHA, L.; LANCHA Jr., A. H. A fadiga do Zoom e dos encontros e reuniões virtuais. Veja Saúde, São Paulo, 18 ago. 2020. Disponível em $<$ https://saude.abril.com.br/blog/com-a-palavra/a-fadiga-do-zoom-e-dosencontros-e-reunioes-virtuais/>. Acesso em: 20 fev. 2021.

MENSAGEIRO LUTERO ONLINE. Cultos presenciais. Disponível em: $<$ https://www.ielb.org.br/noticias/visualizar/7054/atendimento-da-ielb-na -pandemia-e-noticia-no-site-da-ilc\&r=1>. Acesso em: 09 fev. 2021.

PIRAGINE Jr., P. PIB Curitiba na Pandemia. Youtube, 7 out. 2020. Disponível em: $<$ https://www.youtube.com/watch? $\mathrm{v}=\mathrm{Uc} 3 \mathrm{pIMdCyJ} 8 \&$ feature $=\mathrm{emb}$ logo $>$. Acesso em: 09 fev. 2021.

PRADO E SILVA, A. Virtual. In: PRADO E SILVA, A. Novo dicionário brasileiro melhoramentos. São Paulo: Edições Melhoramentos, 1964. p. 880. v. III.

RODRIGUES, G. P.; PORTO, C. M. Realidade virtual: conceitos, evolução, dispositivos e aplicações. Interfaces Científicas, v. 1, n. 3, p. 97-709, jun. 2013. Disponível em: <https://periodicos.set.edu.br/educacao/article/ view/909/414>. Acesso em: 20 fev. 2021. DOI: https://doi.org/10.17564/23163828.2013v1n3p97-109

SANTOS, J. B. R. Koinonia. In: SANTOS, J. B. R. Dicionário Bíblico. São Paulo: Editora Didática Paulista, 2011.p. 97.

SANTOS, J. B. R. Santidade. In: SANTOS, J. B. R. Dicionário Bíblico. São Paulo: Editora Didática Paulista, 2011. p. 464.

SANTOS, L. R. A. A virtualização humana. Prometheus - Journal of Philosophy, v. 10, n. 22, p. 185-198, jan./abr. 2017. Disponível em: < file://C:/ 
Users/User/Downloads/5437-Article\%20Text-18028-3-10-20170526.pdf . Acesso em: 10 fev. 2021. DOI: https://doi.org/10.52052/issn.2176-5960.pro. v10i22.5437

WILliaMS, J. R. Teologia sistemática: uma perspectiva pentecostal. São Paulo: Vida, 2011.

\section{Luiz Tarquinio Pontes}

Doutor em Teologia pela Pontifícia Universidade Católica do Paraná Docente de Filosofia e Teologia na Faculdade Batista Paraná Curitiba / PR - Brasil E-mail: prluiztarquinio@gmail.com

Recebido em: 24/02/21 Aprovado em: 04/06/21 